\title{
Diminished greenhouse warming from Archean methane due to solar absorption lines
}

\author{
B. Byrne ${ }^{1, *}$ and C. Goldblatt ${ }^{1}$ \\ ${ }^{1}$ School of Earth and Ocean Sciences, University of Victoria, Victoria, BC, Canada \\ *now at: Department of Physics, University of Toronto, Toronto, ON, Canada \\ Correspondence to: B. Byrne (bbyrne@physics.utoronto.ca)
}

Received: 29 August 2014 - Published in Clim. Past Discuss.: 29 October 2014

Revised: 9 February 2015 - Accepted: 3 March 2015 - Published: 27 March 2015

\begin{abstract}
Previous research has shown that methane may have been sustained at high concentrations in the Archean atmosphere, helping to offset lower insolation and solve the faint young sun problem. However, recent updates to the HITRAN (High-Resolution Transmission) line database have significantly increased the shortwave absorption by $\mathrm{CH}_{4}$ in comparison to older versions of the database (e.g. HITRAN 2000). Here we investigate the climatological implications of strong shortwave $\mathrm{CH}_{4}$ absorption in an Archean atmosphere rich in $\mathrm{CH}_{4}$. We show that the surface warming at $\mathrm{CH}_{4}$ abundances $>10^{-3}$ is diminished relative to the HITRAN 2000 line data. Strong shortwave absorption also results in a warm stratosphere and lower tropopause. We discuss these results in the context of contemporary research on the Archean climate and how these results could affect the formation of stratospheric clouds and an organic haze.
\end{abstract}

\section{Introduction}

The luminosity of the sun has increased steadily over its main sequence lifetime (Gough, 1981) and was $75-82 \%$ as luminous in the Archean Eon (3.8-2.5 Gya) as today. Despite a dimmer sun, geologic evidence suggests that surface temperatures were similar to today for much of this period (Donn et al., 1965; Sagan and Mullen, 1972). The apparent contradiction between reduced solar luminosity and warm surface temperatures is termed the faint young sun problem or paradox (FYSP). It is generally believed that the Earth was kept warm in the Archean primarily due to elevated greenhouse gas concentrations and thus a stronger greenhouse effect.
Methane $\left(\mathrm{CH}_{4}\right)$ has a long photochemical lifetime of $10^{3}$ to $10^{4} \mathrm{yr}$ in low-oxygen atmospheres (Zahnle, 1986). Given the long atmospheric lifetime, concentrations of $\approx$ 10 ppmv could have been sustained by impacts from space and geologic sources in the Archean (Kasting, 2005). Much higher concentrations may have been sustained by anaerobic ecosystems. Using a photochemical-ecosystem model, Kharecha et al. (2005) found that biogenic methane fluxes were likely 1/3-2.5 times modern values. They find that these fluxes could have sustained atmospheric concentrations of 100 to 35000 ppmv (depending on the rate of hydrogen escape).

Thus, it has been proposed that methane played an important role in the Archean greenhouse and may have been partially responsible for the warm climate. At high $\mathrm{CH}_{4} / \mathrm{CO}_{2}$ ratios, photochemical reactions have been shown to produce an organic haze with a strong anti-greenhouse effect (Zahnle, 1986), possibly limiting the warming ability of $\mathrm{CH}_{4}$ at very high concentrations.

Recent updates to the HITRAN database (Rothman et al., 2013; Brown et al., 2013) have significantly increased the magnitude of shortwave absorption by $\mathrm{CH}_{4}$ at high concentration (Byrne and Goldblatt, 2014), particularly between 5500 and 9000 and around $11000 \mathrm{~cm}^{-1}$ (Fig. 1). This results in significant shortwave absorption in the upper troposphere and stratosphere at high $\mathrm{CH}_{4}$ concentrations. It should be noted that there is still a considerable amount of missing shortwave line data, so the shortwave absorption by $\mathrm{CH}_{4}$ is likely still being underestimated.

Strong shortwave absorption is expected to have a significant effect on the atmospheric temperature profile. Increased shortwave absorption in the stratosphere limits the amount 


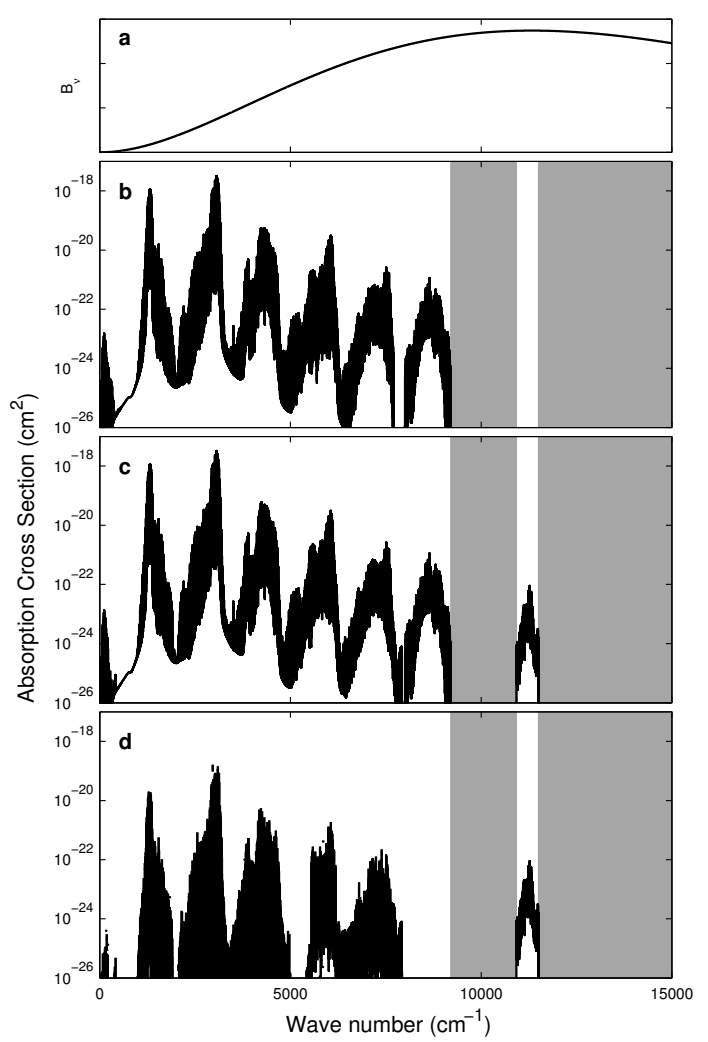

Figure 1. $\mathrm{CH}_{4}$ solar spectra. (a) Emission spectrum for an object of $5777 \mathrm{~K}$ (effective emitting temperature of modern Sun). (b) HITRAN 2000 and (c) HITRAN 2012 absorption cross sections for $\mathrm{CH}_{4}$. (d) Difference in absorption cross sections between HITRAN 2012 and HITRAN 2000. Shaded regions indicate where no data exists.

of radiation that reaches the surface. As such, there is a negative forcing on the surface which acts to decrease surface temperatures. Thus, it is expected that previous estimates of the warming due to $\mathrm{CH}_{4}$ have been overestimated at high concentrations. Furthermore, solar absorption in the stratosphere leads to stratospheric warming, which diminishes the effect of greenhouse gases in the stratosphere.

In this paper, we run a radiative convective model ( $\mathrm{RCM})$ using the HITRAN 2000 and 2012 databases to examine the effect that updates to the HITRAN database have on the atmospheric profile and warming from $\mathrm{CH}_{4}$. We choose the HITRAN 2000 version for comparison because most existing literature for $\mathrm{CH}_{4}$ in the Archean uses shortwave absorption data which predates this version (Pavlov et al., 2000; Haqq-Misra et al., 2008; these studies do include a parameterization of visible/near-IR absorption by $\mathrm{CH}_{4}$, where HITRAN data is missing, but the absorption is still strongly underestimated). In Sect. 2, we describe our general methods. In Sect. 3, we provide our results. We examine the surface temperature and atmospheric profile as a function of $\mathrm{CH}_{4}$. In Sect. 4, we discuss the possible climatic consequences of our results. We discuss how a warmer stratosphere may affect stratospheric clouds and a hypothetical organic haze.

\section{Methods}

\subsection{Radiative transfer model}

We use the Spectral Mapping for Atmospheric Radiative Transfer (SMART) code, written by David Crisp (Meadows and Crisp, 1996), for our radiative transfer calculations. This code works at a line-by-line resolution but uses a spectral mapping algorithm to treat different wave number regions with similar optical properties together, giving significant savings in computational cost. We evaluate the radiative transfer in the range $50-100000 \mathrm{~cm}^{-1}(0.1-200 \mu \mathrm{m})$ as a combined solar and thermal calculation. Line data for all radiatively active gases are taken from the HITRAN 2012 and 2000 databases.

\subsection{Radiative Convective Model}

The RCM used in this work derives from Goldblatt (2008) and Goldblatt et al. (2009). A "hard convective adjustment" is used, whereby the tropospheric structure is set as the moist adiabatic lapse rate, so surface and tropospheric temperature are represented by a single degree of freedom. The stratosphere is radiatively adjusted and the tropopause position is adjusted.

The SMART radiative transfer code is very computationally expensive. Hence the Newton-Raphson method used previously (Goldblatt et al., 2009) is too expensive, requiring a separate radiative transfer run for each degree of freedom (model level). Therefore, we derive a new numerical method, which diagnoses a grey emissivity for each layer and solves a linearized set of equations to adjust the model temperature. The algorithm is described in full in the appendix. For test cases with a grey atmosphere radiative transfer code, this gave convergence in 3-4 iterations. Unfortunately, the diagnosis of pseudo-grey emissivities for each layer from the real-gas radiation field was not as effective as we hoped and introduced some numerical instabilities. We introduced numerical smoothing and damping at each iteration to control the instability. Convergence was typically obtained in 20-30 iterations.

Water vapour was parametrized as in Manabe and Wetherald (1967). Relative humidity $(h)$ is given by

$h=h_{\star}\left(\frac{Q-0.02}{1-0.02}\right)$,

where $h_{\star}=0.77, Q=p / p_{\star}$, and $p_{\star}$ is surface pressure. When $Q$ is smaller than 0.02 , the relative humidity becomes negative; thus, it is necessary to specify a minimum humidity distribution for small $Q$ values. Manabe and Wetherald (1967) determine a minimum mixing 
ratio of water vapour to be $3 \times 10^{-6} \mathrm{gg}^{-1}$ of air. We take this as the minimum mixing ratio for a "mid- $\mathrm{H}_{2} \mathrm{O}$ " set of calculations. Since the saturation vapour pressure is proportional to temperature and we expect significant warming in the upper troposphere and stratosphere from shortwave absorption by $\mathrm{CH}_{4}$, the relative humidity parametrization may significantly affect the amount of atmospheric $\mathrm{H}_{2} \mathrm{O}$. The $\mathrm{H}_{2} \mathrm{O}$ concentrations would then affect the strength of the $\mathrm{H}_{2} \mathrm{O}$ greenhouse. Furthermore, elevated high troposphere and stratospheric water vapour concentrations would increase the emission level to space from $\mathrm{H}_{2} \mathrm{O}$ and thus would promote cooling of this level. A further complication is that methane oxidation is a significant stratospheric moisture source, and this would be enhanced with higher methane abundances.

To examine the sensitivity of our results to the parametrization of $\mathrm{H}_{2} \mathrm{O}$, we perform a "low- $\mathrm{H}_{2} \mathrm{O}$ " set of calculations, for which we reduce the minimum mixing ratio of water vapour by a factor of 1000 to $3 \times 10^{-9} \mathrm{~g} \mathrm{~g}^{-1}$ of air, and a "high- $\mathrm{H}_{2} \mathrm{O}$ " set of calculations, for which we increase the minimum mixing ratio of water vapour by a factor of 10 to $3 \times 10^{-5} \mathrm{~g} \mathrm{~g}^{-1}$ of air. We attempted an additional set of runs in which the $\mathrm{H}_{2} \mathrm{O}$ mixing ratio above the tropopause was set at the tropopause value but found it to be unstable in our model.

\subsection{Runs}

Gas amounts are given in abundances, $a$, relative to the modern atmosphere ( $1 \mathrm{bar}$, molecular weight of $28.97 \mathrm{~g} \mathrm{moles}^{-1}$, total moles $\left(n_{0}\right)$ of $\left.\approx 1.8 \times 10^{20}\right)$. Thus, $a=n_{\text {gas }} / n_{0}$. For our experiments we add gas abundances to background $\mathrm{N}_{2}$ partial pressure $(0.8 \mathrm{bar})$, increasing the atmospheric pressure.

We calculate the equilibrium temperature profile over many $\mathrm{CH}_{4}$ abundances to be in the range of $10^{-6}$ to $10^{-2}$ with a solar constant of $0.8 S_{0}$. We perform sets of runs with background $\mathrm{CO}_{2}$ abundances of $10^{-3}, 10^{-2}$, and $10^{-1}$ for the high- $\mathrm{H}_{2} \mathrm{O}$, mid- $\mathrm{H}_{2} \mathrm{O}$, and $\mathrm{low}-\mathrm{H}_{2} \mathrm{O}$ water vapour parametrizations. These sets of runs are performed with both the HITRAN 2000 and HITRAN 2012 line data, giving a total of 18 sets of runs. The reason for running sets with varying $\mathrm{CO}_{2}$ abundances is that $\mathrm{CO}_{2}$ cools the upper atmosphere and, thus, we would like to examine whether cooling by $\mathrm{CO}_{2}$ or warming by $\mathrm{CH}_{4}$ dominates.

\section{Results}

\subsection{Modern atmosphere and climate sensitivity}

To test our RCM and diagnose the climate sensitivity, we calculate the equilibrium temperature profile with pre-industrial (280 ppmv) and doubled (560 ppmv) $\mathrm{CO}_{2}$. We find that our model performs well in recreating the pre-industrial atmospheric profiles (Fig. 2). For low- $\mathrm{H}_{2} \mathrm{O}$, mid- $\mathrm{H}_{2} \mathrm{O}$, and high$\mathrm{H}_{2} \mathrm{O}$ parametrizations, we find the pre-industrial surface temperature to be $288.4,288.5$, and $291.4 \mathrm{~K}$. The temperature change for a doubling of $\mathrm{CO}_{2}$ is $1.76 \mathrm{~K}$ for low $\mathrm{H}_{2} \mathrm{O}, 1.75 \mathrm{~K}$

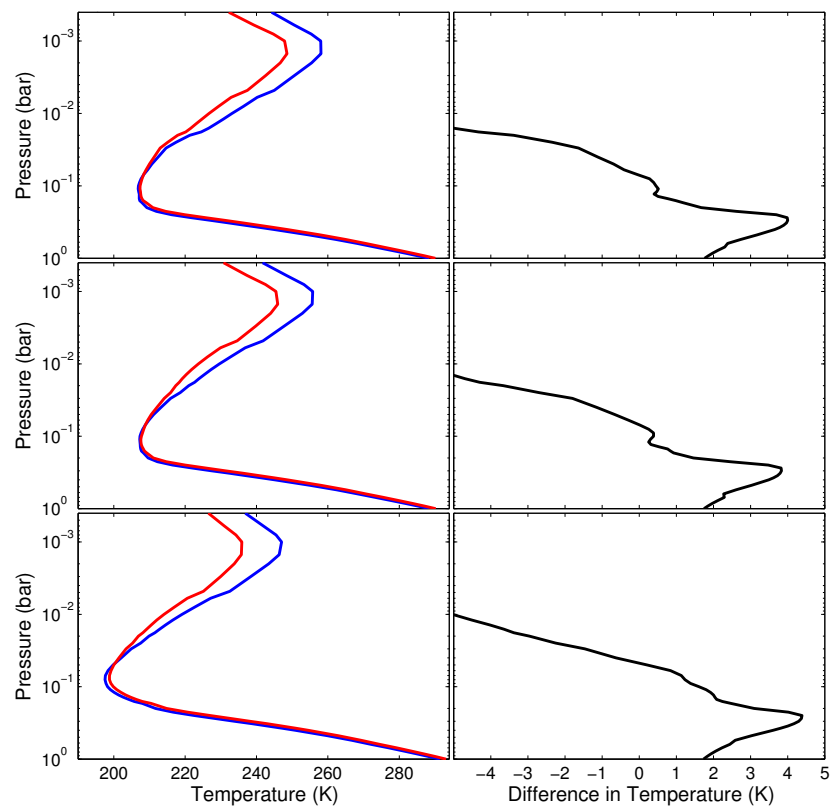

Figure 2. Modern Earth temperature profiles. Pre-industrial (blue) and doubled $\mathrm{CO}_{2}$ (red) temperature profiles for (a) low-, (c) mid-, and (e) high- $\mathrm{H}_{2} \mathrm{O}$ parametrizations. Corresponding changes in temperature for (b) low-, (d) mid-, and (f) high- $\mathrm{H}_{2} \mathrm{O}$ parametrizations. Grey line shows the global and annual mean modern-day temperature profile.

for mid- $\mathrm{H}_{2} \mathrm{O}$, and $1.73 \mathrm{~K}$ for high $\mathrm{H}_{2} \mathrm{O}$. These are within the range of climate sensitivities given by the IPCC (2013, $1.5-4.5 \mathrm{~K}$ ) but are less than the best guess of $3 \mathrm{~K}$. The climate sensitivity is largest for the low- $\mathrm{H}_{2} \mathrm{O}$ parametrization because the water vapour change is larger.

\subsection{Error estimates}

We take the model to be converged when the net flux above the tropopause $(\Delta F)$ is less than $0.2 \mathrm{~W} \mathrm{~m}^{-2}$ for every layer above the tropopause. In cases for which this could not be achieved within reasonable limits on computational cost, we estimate the precision of runs with a lower convergence threshold.

To do this we examined the difference in temperature for unconverged iterations of a converged run. The error in surface temperature for each unconverged iteration was found by taking the difference in surface temperature between the converged and unconverged iterations $(\Delta T)$. The maximum net flux above the tropopause was plotted as a function of surface temperature error (Fig. 3). To estimate the largest surface temperature error for a given maximum net flux above the tropopause, we found a linear slope which contained all of the points. All of the points fit within a region bounded by a slope of $\Delta F=2 \Delta T$. Thus, uncertainty in temperature is taken to be $\Delta T=\frac{1}{2} \Delta F$. 


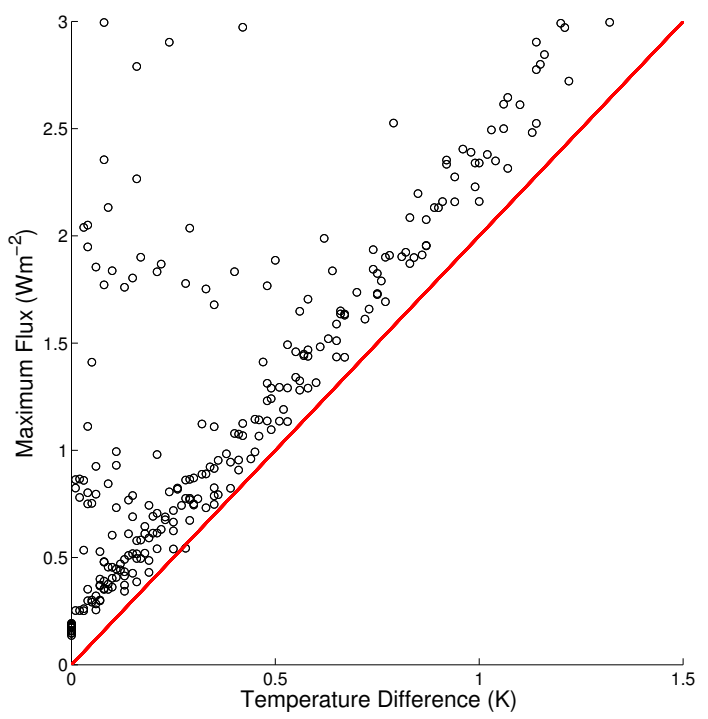

Figure 3. Error Estimate. Maximum flux above the tropopause $(\Delta F)$ as a function of difference in surface temperature $(\Delta T)$. Red line has slope of $\Delta F=2 \Delta T$.

\subsection{Surface temperature}

We examine surface temperature as a function of $\mathrm{CH}_{4}$ for each set of runs (Fig. 4). For all cases, there are significant differences between runs with HITRAN 2000 and HITRAN 2012 line data. At low $\mathrm{CH}_{4}$ abundances, the surface temperature is slightly warmer $(\approx 1 \mathrm{~K})$ using the HITRAN 2012 database relative to the HITRAN 2000 database, due to additional longwave absorption lines added to the HITRAN 2012 database. Additional $\mathrm{CH}_{4}$ shortwave absorption in HITRAN 2012 starts to become evident at $\mathrm{CH}_{4}$ above $10^{-4}$ and becomes significant at concentrations above $10^{-3}$. For a $\mathrm{CH}_{4}$ increase from $10^{-3}$ to $10^{-2}$, the warming is $4.8-6.4 \mathrm{~K}$ using HITRAN 2000 line data and $-0.6-2.5 \mathrm{~K}$ using 2012 line data. Thus, the ability of $\mathrm{CH}_{4}$ to warm the surface is significantly diminished above $10^{-3}$.

The difference in absorption by $\mathrm{CO}_{2}$ and $\mathrm{H}_{2} \mathrm{O}$ is quite small between the two databases. Although, many new lines have been added to both $\mathrm{CO}_{2}$ and $\mathrm{H}_{2} \mathrm{O}$ databases, they do not provide a large radiative effect in the regime we examined. The differences between HITRAN versions result in a small increase to the greenhouse strength between versions, increasing the surface temperature by roughly $1 \mathrm{~K}$ in the regimes we examined.

The surface temperature is sensitive to the $\mathrm{H}_{2} \mathrm{O}$ parametrization used. At low $\mathrm{CH}_{4}$ abundances, the atmosphere is cold and the $\mathrm{H}_{2} \mathrm{O}$ abundances decrease rapidly with altitude to the minimum allowed abundance (Fig. 5), resulting in large differences in the amount of atmospheric $\mathrm{H}_{2} \mathrm{O}$ between the difference parametrizations. Thus, the water vapour greenhouse effect is much stronger for higher min- imum allowed abundances, which results in warmer surface temperatures.

Large atmospheric methane abundances cause atmospheric warming above a pressure level of $0.3 p_{\star}$ (see Sect. 3.4). For our low- and mid- $\mathrm{H}_{2} \mathrm{O}$ parametrizations, this causes the amount of water here to increase, strengthening the greenhouse effect and causing surface warming. However, for our high- $\mathrm{H}_{2} \mathrm{O}$ parametrization, the water vapour is already at a maximum here, and we see the consequence of methane absorption in isolation. Between methane abundances of $3 \times 10^{-4}$ and $1 \times 10^{-2}$, there is a surface cooling of $2 \mathrm{~K}$ with the HITRAN 2012 database as compared to a warming of $7 \mathrm{~K}$ using the HITRAN 2000 database.

The parametrizations of relative humidity used here are simplistic and may not properly represent the relative humidity structure for an Archean atmosphere with high $\mathrm{CH}_{4}$. Water vapour moves from the troposphere to the stratosphere though complicated dynamical processes. On the modern Earth, water vapour enters the stratosphere through the extremely cold tropical tropopause (Brewer, 1949; Newell and Gould-Stewart, 1981). Resolving atmospheric dynamics would be required to correctly estimate stratospheric water vapour. Furthermore, methane oxidation is a significant source of stratospheric water vapour, and this will be a much larger source when there is more methane. Hence, photochemistry should be treated too.

The surface temperatures calculated using HITRAN 2000 line data agree well with the results of Haqq-Misra et al. (2008). For a $\mathrm{CO}_{2}$ abundance of $10^{-2}$ and a $\mathrm{CH}_{4}$ increase from $10^{-5}$ to $10^{-2}$, Haqq-Misra et al. (2008) found a temperature increase of $11.5 \mathrm{~K}$ and we find a temperature increase of 12.6 K (low $\mathrm{H}_{2} \mathrm{O}$ ), $11.2 \mathrm{~K}$ (mid- $\mathrm{H}_{2} \mathrm{O}$ ), and $9.8 \mathrm{~K}$ (high $\mathrm{H}_{2} \mathrm{O}$ ). This is much diminished with the HITRAN 2012 line data; for the same scenario we find a temperature increase of $8.1 \mathrm{~K}$ (low $\mathrm{H}_{2} \mathrm{O}$ ), $6.7 \mathrm{~K}$ (mid- $\mathrm{H}_{2} \mathrm{O}$ ), and $3.4 \mathrm{~K}\left(\right.$ high $\mathrm{H}_{2} \mathrm{O}$ ).

\subsection{Atmospheric temperature structure}

Increased shortwave absorption by $\mathrm{CH}_{4}$ warms the stratosphere (altitudes above $\approx 0.3 p_{\star}$ ) relative to the HITRAN 2000 line data (Fig. 6). The warming as a function of $\mathrm{CH}_{4}$ is roughly $2-5 \mathrm{~K}$ for $10^{-4}, 10-20 \mathrm{~K}$ for $10^{-3}$, and $20-35 \mathrm{~K}$ for $10^{-2}$. The warming also causes the tropopause to lower with increasing $\mathrm{CH}_{4}$.

Elevated $\mathrm{CO}_{2}$ acts to cool the stratosphere and thus counteracts warming by $\mathrm{CH}_{4}$. In general, warming by $\mathrm{CH}_{4}$ is the dominant effect, although differences in the temperature structure at different $\mathrm{CO}_{2}$ concentrations are apparent. The most significant differences are as follows: (1) the difference in stratospheric temperature between the HITRAN databases is largest at low $\mathrm{CO}_{2} ;(2)$ a temperature inversion appears for a $\mathrm{CO}_{2}$ abundance of $10^{-3}$ but does not form at higher abundances; and (3) the tropopause is lower with less $\mathrm{CO}_{2}$ (for example, with a $\mathrm{CH}_{4}$ abundance of $10^{-2}$, the tropopause is 


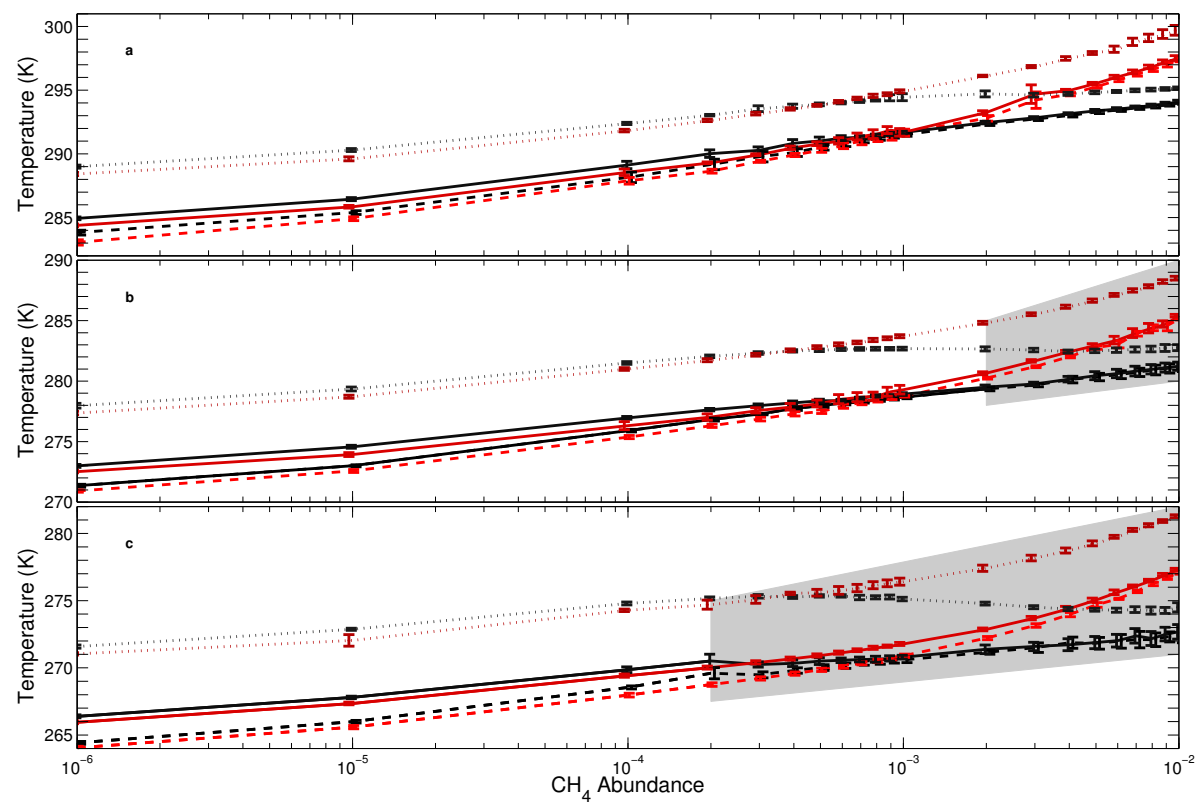

Figure 4. Surface temperature as a function of $\mathrm{CH}_{4}$. The three panels correspond to $\mathrm{CO}_{2}$ abundances of (a) $10^{-1}$, (b) $10^{-2}$, and (c) $10^{-3}$. Dashed lines are for the low $-\mathrm{H}_{2} \mathrm{O}$ parametrization, solid lines are for the mid- $\mathrm{H}_{2} \mathrm{O}$ parametrization, and dotted lines are for the high- $\mathrm{H}_{2} \mathrm{O}$ parametrization. Black lines are for the HITRAN 2012 database and red lines are for the HITRAN 2000 database. Shaded regions indicate the possibility of an organic haze. Error bars are plotted corresponding to the error estimates from Sect. 3.2.

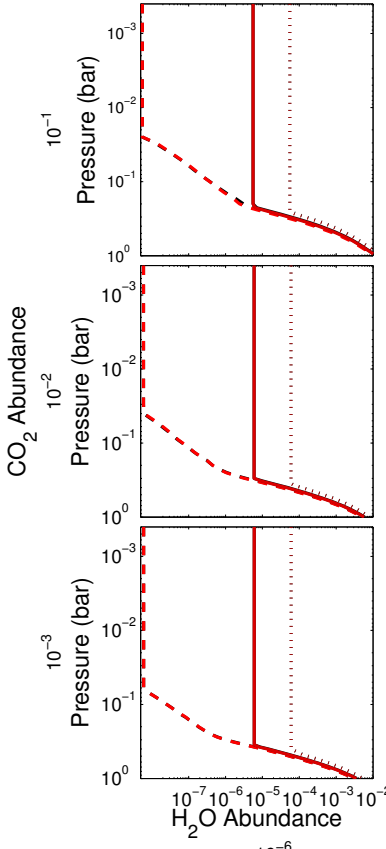

$10^{-6}$
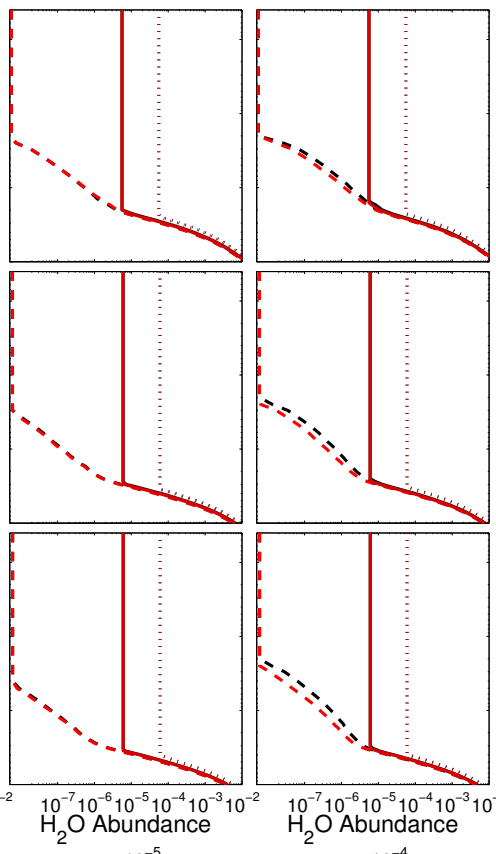

$10^{-5}$

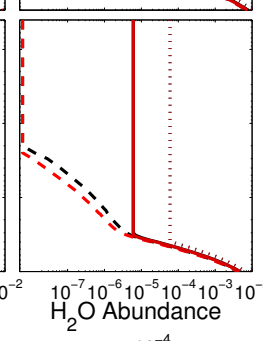

$\mathrm{CH}_{4}$ Abundance
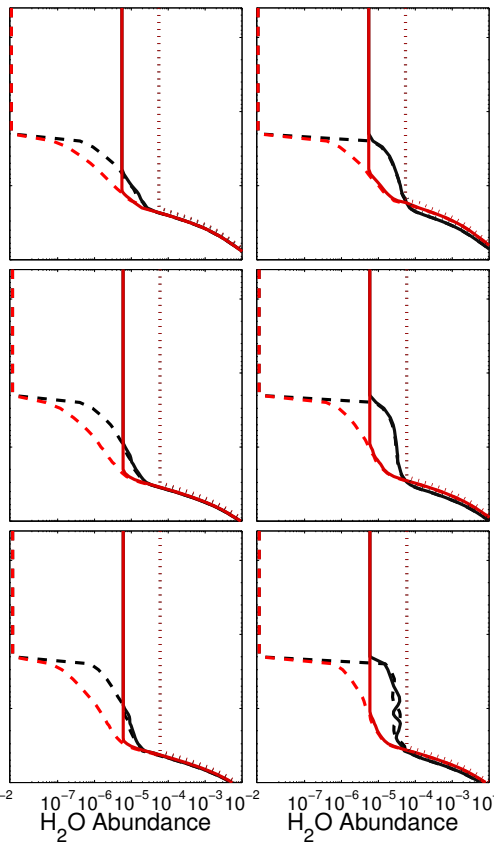

$10^{-3}$

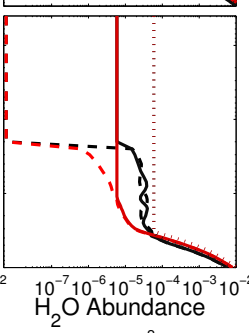

$10^{-2}$

Figure 5. Atmospheric $\mathrm{H}_{2} \mathrm{O}$ Profiles. Equilibrium $\mathrm{H}_{2} \mathrm{O}$ abundances as a function of $\mathrm{CO}_{2}$ and $\mathrm{CH}_{4}$ abundances. Line types and colours are as in Fig. 4. 


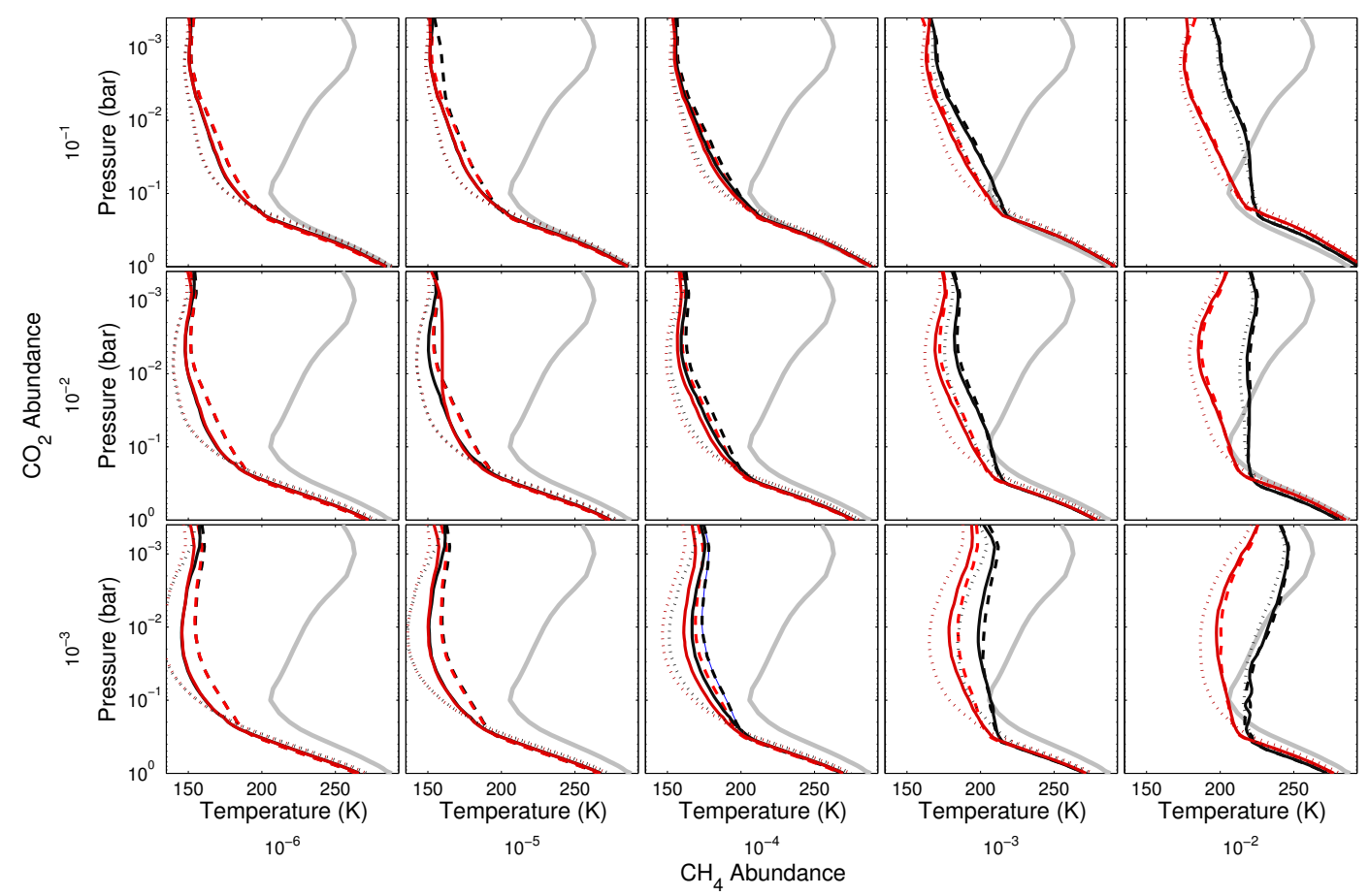

Figure 6. Atmospheric temperature profiles. Equilibrium temperature profiles $(\mathrm{K})$ as functions of $\mathrm{CO}_{2}$ and $\mathrm{CH}_{4}$ abundances. $\mathrm{Line}$ types and colours are as in Fig. 4. Grey line shows the global and annual mean temperature profile for the modern atmosphere.

at $\approx 0.4 p_{\star}$ for $10^{-3}$ of $\mathrm{CO}_{2}, \approx 0.3 p_{\star}$ for $10^{-2}$ of $\mathrm{CO}_{2}$, and $\approx 0.2 p_{\star}$ for $10^{-1}$ of $\mathrm{CO}_{2}$ ).

Longwave emissions to space from $\mathrm{H}_{2} \mathrm{O}$ act to cool the stratosphere. At low $\mathrm{CH}_{4}$, higher parametrized $\mathrm{H}_{2} \mathrm{O}$ abundances result in a cooler stratosphere. In contrast to the surface temperature, the $\mathrm{H}_{2} \mathrm{O}$ parametrization has only a minor effect on the temperature structure in the stratosphere at high $\mathrm{CH}_{4}$ concentrations. This is because the $\mathrm{H}_{2} \mathrm{O}$ concentration is similar for all cases at high $\mathrm{CH}_{4}$ (Fig. 5).

\section{Discussion}

\subsection{Stratospheric ice clouds}

In the contemporary modelling of the Archean atmosphere, the removal of $\mathrm{O}_{2}$ and $\mathrm{O}_{3}$ and increased $\mathrm{CO}_{2}$ result in decreased static stability of the stratosphere (Rossow et al., 1982; Wolf and Toon, 2013; Kunze et al., 2014). Thus, deep convective mass and water fluxes are enhanced for the Archean (Wolf and Toon, 2013). However, as shown above, high $\mathrm{CH}_{4}$ results in a stable stratosphere. Thus, it is worth discussing the effect that this increased stability would have on studies of the Archean climate.

Modelling studies have found that the removal of $\mathrm{O}_{2}$ and $\mathrm{O}_{3}$ results in a decrease in static stability and higher penetration of convection, which produces increased cirrus ice clouds in the stratosphere (Rossow et al., 1982; Wolf and Toon, 2013; Kunze et al., 2014). Wolf and Toon (2013) found that replacing $\mathrm{O}_{2}$ and $\mathrm{O}_{3}$ with $\mathrm{N}_{2}$ in the present-day atmosphere produces a $3.9 \mathrm{~W} \mathrm{~m}^{-2}$ longwave radiative forcing from clouds. However, the contribution of ice clouds to the greenhouse effect in the Archean is reduced due to the saturation of longwave spectral bands from elevated $\mathrm{CO}_{2}$ concentrations despite increased cloud fractions. Thus, it is unlikely that the absence of these clouds would have a large effect on the Archean climate.

\subsection{Organic haze}

Photochemical models have found that an organic haze is produced by photolysis as $\mathrm{CH}_{4}$ concentrations approach the $\mathrm{CO}_{2}$ concentration in a low- $\mathrm{O}_{2}$ atmosphere (Kasting et al., 1983; Zahnle, 1986). Organic haze has been predicted by photochemical modelling at $\mathrm{CH}_{4} / \mathrm{CO}_{2}$ ratios larger than 1 (Zahnle, 1986), and laboratory experiments have found that organic haze could form at $\mathrm{CH}_{4} / \mathrm{CO}_{2}$ ratios as low as $0.2-$ 0.3 (Trainer et al., 2004, 2006). The organic haze would likely produce a significant anti-greenhouse effect by reflecting solar radiation while being transparent to infrared radiation, although the organic haze may also have shielded greenhouse gases from photolysis (such as $\mathrm{NH}_{3}$ Wolf and Toon, 2010) and produced other greenhouse gases (such as $\mathrm{C}_{2} \mathrm{H}_{6}$, Haqq-Misra et al., 2008).

The precise radiative effect that an organic haze would have had on the early Earth's climate is poorly quantified. Further, the relative humidity at which the haze 
formed may have effected the radiative impacts of the haze. Hasenkopf et al. (2011) performed laboratory experiments on the formation of haze particles via ultraviolet photolysis over a range of relative humidities and found that increasing relative humidity increases the cooling effect of the haze particles. In contemporary Archean climate simulations, exceedingly low temperatures above the tropopause mean that saturation vapour pressure is quite low. Thus, despite having little water vapour, relative humidities grow large above the tropopause (Wolf and Toon, 2013). However, stratospheric warming would increase the saturation vapour pressure and lower the relative humidities, which would effect the formation of an organic haze; higher relative humidity may cause fractal particles to collapse into spheres, while lower relative humidity would allow the fractal shape to be better preserved (Wolf, 2014).

Geological constraints, based on the mass balance of weathering palaeosols, have suggested that the atmospheric $\mathrm{CO}_{2}$ partial pressure was in the range of $0.003-0.02$ bar in the late Archean (2.69 Gyr ago; Driese et al., 2011). Given that an organic haze could form at $\mathrm{CH}_{4} / \mathrm{CO}_{2}$ ratios as low as $0.2-0.3$, this would imply that an organic haze would form at $\mathrm{CH}_{4}$ abundances greater than $6 \times 10^{-4}-6 \times 10^{-3}$. In the presence of an organic haze, shortwave absorption by $\mathrm{CH}_{4}$ would likely be of less importance. However, at the upper limit of this range, a $\mathrm{CH}_{4}$ abundance of $6 \times 10^{-3}$ results in a significant $(3-4 \mathrm{~K})$ difference in surface warming between HITRAN versions. Thus, given the constraints on atmospheric $\mathrm{CO}_{2}$ and organic haze, the calculated reduction in surface warming due to improved line data may have been radiatively important throughout the Archean. Furthermore, atmospheric $\mathrm{CO}_{2}$ constraints only exist for the latest Archean (2.69 Gyr ago; Driese et al., 2011). The solar luminosity used in this study ( $80 \%$ of today's value) occurred 2.86 Gyr ago (Eq. 1, Feulner, 2012), which is $170 \mathrm{Myr}$ before the earliest constraint on $\mathrm{CO}_{2}$ (2.69 Gyr ago, Driese et al., 2011). Thus, $\mathrm{CO}_{2}$ may have been significantly higher than 0.02 bar at this time, meaning atmospheric $\mathrm{CH}_{4}$ concentrations larger than $6 \times 10^{-3}$ bar could have existed without haze formation.

\section{Conclusions}

Increased shortwave absorption by $\mathrm{CH}_{4}$ between the HITRAN 2000 and HITRAN 2012 databases significantly reduces the efficacy of $\mathrm{CH}_{4}$ in warming the climate at abundances above $10^{-3}$. The quantitative difference in warming is sensitive to the parametrization of relative humidity and the magnitude of water vapour change in our model. If the water vapour change is small (high $\mathrm{H}_{2} \mathrm{O}$ ), then the surface temperature remains roughly constant or decreases with increasing $\mathrm{CH}_{4}$ above an abundance of $10^{-3}$. With a large $\mathrm{H}_{2} \mathrm{O}$ change the surface temperature continues to increase with $\mathrm{CH}_{4}$, but to a much lesser extent. These results are sensitive to our simple relative humidity parametrization; a GCM (general circulation model) study with well-resolved cross-tropospheric moisture transport and a parametrized moisture source from methane oxidation might be enlightening.

Significantly enhanced solar absorption here derives from the inclusion of the $11000 \mathrm{~cm}^{-1}$ methane band in HITRAN 2012. However, there are still significant regions of missing data, especially around the $10000 \mathrm{~cm}^{-1}(1 \mu \mathrm{m})$ methane band. Thus, we expect that our results here actually underestimate the true amount of absorption of sunlight by methane: surface cooling, stratospheric warming, and tropopause lowering may all be larger than our calculations indicate.

The increased shortwave absorption significantly increases the stratospheric temperature and lowers the tropopause at high $\mathrm{CH}_{4}$ concentrations. All relative humidity parametrizations give high stratospheric $\mathrm{H}_{2} \mathrm{O}$ at high $\mathrm{CH}_{4}$ abundances and similar temperature structures. The warm temperature structure would reduce the likelihood of stratospheric ice clouds, which have formed in some GCM studies of the Archean climate. They would also change the relative humidity of the stratosphere from those values seen in GCMs. Since the radiative properties of an organic haze are sensitive to the relative humidity at which it forms, this may significantly effect the radiative properties of such a haze. 


\section{Appendix A: Radiative adjustment algorithm}

The energy budget of an atmospheric layer is balanced by absorbed shortwave radiation, absorbed upwelling $\left(D^{+}\right)$ and downwelling $\left(D^{-}\right)$longwave radiation, and emitted upwelling $\left(B^{+}\right)$and downwelling $\left(B^{-}\right)$longwave radiation.

The longwave radiation emitted at each atmospheric level is very sensitive to temperature. For simplicity, we assume that the emission from a layer $j$ is independent of frequency and emitted as blackbody radiation (i.e. grey gas):

$F_{j}^{+}=a_{j}^{+} \sigma T_{j}^{4}, F_{j}^{-}=a_{j}^{-} \sigma T_{j}^{4}$,

where $a_{j}$ is the absorptivity/emissivity of a layer and $T_{j}$ is the temperature of layer $j$. Since gases are not grey, we have to diagnose $a_{j}$ as a pseudo-absorptivity (see Sect. A1).

The atmospheric profile given as an input to SMART consists of $N$ levels, resulting in an atmosphere with $N-1$ atmospheric layers. A layer with index $j$ is bounded above by level $j$ and below by level $j+1$. We can write the fluxes absorbed and emitted from layer $j$ as

$$
\begin{aligned}
& D_{j}^{-}\left(T_{1}, \ldots, T_{j-2}, T_{j-1}\right)=\sigma a_{j}^{-} \sum_{n=1}^{j-1}\left[a_{n}^{-} T_{n}^{4} \prod_{m=n+1}^{j-1} t_{m}^{-}\right], \\
& D_{j}^{+}\left(T_{j+1}, T_{j+2}, \ldots, T_{\mathrm{surf}}\right)=\sigma a_{j}^{+}\left(\sum_{n=j+1}^{N-1}\left[a_{n}^{+} T_{n}^{4} \prod_{m=j+1}^{n-1} t_{m}^{+}\right]\right. \\
& \left.+a_{\text {surf }}^{+} T_{\text {surf }}^{4} \prod_{m=j+1}^{N-1} t_{m}^{+}\right), B_{j}^{-}\left(T_{j}\right)=\sigma a_{j}^{-} \sigma T_{j}^{4}, \\
& B_{j}^{+}\left(T_{j}\right)=\sigma a_{j}^{+} \sigma T_{j}^{4},
\end{aligned}
$$

where $t_{j}=1-a_{j}$. Thus, the net absorbed flux ( $\left.A_{\text {net }}\right)$ at layer $j$ is

$$
\begin{aligned}
A_{\text {net, }, j} & =A_{\mathrm{SW}, j}+A_{\mathrm{LW}, j}, \\
& =A_{\mathrm{SW}, j}+D_{j}^{-}+D_{j}^{+}-B_{j}^{-}-B_{j}^{+} .
\end{aligned}
$$

Let an initial atmospheric temperature profile have a net absorbed radiation $A_{\text {net, } j, 0}$ and temperature $T_{j, 0}$ for each layer $j$. Assume that there exists an equilibrium atmospheric temperature structure such that $A_{\text {net }, j}=0$ for all $j$. The layer temperatures for the equilibrium profile, $T_{\mathrm{E}}$, can then be written in terms of the initial layer temperatures and a temperature perturbation:

$T_{\mathrm{E}, j}=T_{0, j}+\delta T_{j}$.
The energy budget for the initial profile, for layer $j$, is given as

$$
\begin{aligned}
& A_{\text {net }, j, 0}=A_{\mathrm{SW}, j}+D_{j}^{-}\left(T_{0,1}, \ldots, T_{0, j-2}, T_{0, j-1}\right) \\
& +D_{j}^{+}\left(T_{0, j+1}, T_{0, j+2}, \ldots, T_{0, \mathrm{surf}}\right)-B_{j}^{-}\left(T_{0, j}\right)-B_{j}^{+}\left(T_{0, j}\right), \\
& =A_{\mathrm{SW}, j}+\sigma a_{j}^{-} \sum_{n=1}^{j-1}\left[a_{n}^{-} T_{0, n}^{4} \prod_{m=n+1}^{j-1} t_{m}^{-}\right] \\
& +\sigma a_{j}^{+}\left(\sum_{n=j+1}^{N-1}\left[a_{n}^{+} T_{0, n}^{4} \prod_{m=j+1}^{n-1} t_{m}^{+}\right]+a_{\mathrm{surf}}^{+} T_{\text {surf }}^{4} \prod_{m=j+1}^{N-1} t_{m}^{+}\right) \\
& -\sigma a_{j}^{-} \sigma T_{0, j}^{4}-\sigma a_{0, j}^{+} \sigma T_{j}^{4},
\end{aligned}
$$

and the equilibrium profile (no net energy absorbed) is given as

$$
\begin{aligned}
& 0=A_{\mathrm{SW}, j}+D_{j}^{-}\left(T_{0,1}+\delta T_{1}, \ldots, T_{0, j-2}+\delta T_{j-2}, T_{0, j-1}\right. \\
& \left.+\delta T_{j-1}\right)+D_{j}^{+}\left(T_{0, j+1}+\delta T_{j+1}, T_{0, j+2}+\delta T_{j+2}, \ldots,\right. \\
& \left.T_{0, \text { surf }}+\delta T_{\mathrm{surf}}\right)-B_{j}^{-}\left(T_{0, j}+\delta T_{j}\right)-B_{j}^{+}\left(T_{0, j}+\delta T_{j}\right) . \\
& =A_{\mathrm{SW}, j}+\sigma a_{j}^{-} \sum_{n=1}^{j-1}\left[a_{n}^{-}\left(T_{0, n}+\delta T_{n}\right)^{4} \prod_{m=n+1}^{j-1} t_{m}^{-}\right] \\
& +\sigma a_{j}^{+}\left(\sum_{n=j+1}^{N-1}\left[a_{n}^{+}\left(T_{0, n}+\delta T_{n}\right)^{4} \prod_{m=j+1}^{n-1} t_{m}^{+}\right]\right. \\
& \left.+a_{\text {surf }}^{+}\left(T_{\text {surf }}+\delta T_{\text {surf }}\right)^{4} \prod_{m=j+1}^{N-1} t_{m}^{+}\right) \\
& -\sigma a_{j}^{-} \sigma\left(T_{0, j}+\delta T_{j}\right)^{4}-\sigma a_{0, j}^{+} \sigma\left(T_{0, j}+\delta T_{j}\right)^{4} .
\end{aligned}
$$

Now, subtract Eq. (A6) from Eq. (A5):

$$
\begin{aligned}
& A_{\text {net }, j, 0}=\sigma a_{j}^{-} \sum_{n=1}^{j-1}\left[a_{n}^{-}\left(T_{0, n}^{4}-\left(T_{0, n}+\delta T_{n}\right)^{4}\right) \prod_{m=n+1}^{j-1} t_{m}^{-}\right] \\
& +\sigma a_{j}^{+}\left(\sum_{n=j+1}^{N-1}\left[a_{n}^{+}\left(T_{0, n}^{4}-\left(T_{0, n}+\delta T_{n}\right)^{4}\right)^{4} \prod_{m=j+1}^{n-1} t_{m}^{+}\right]\right) \\
& +\sigma a_{j}^{+}\left(a_{\text {surf }}^{+}\left(T_{\text {surf }}^{4}-\left(T_{\text {surf }}+\delta T_{\text {surf }}\right)^{4}\right) \prod_{m=j+1}^{N-1} t_{m}^{+}\right) \\
& -\sigma a_{j}^{-} \sigma\left(T_{0, j}^{4}-\left(T_{0, j}+\delta T_{j}\right)^{4}\right) \\
& -\sigma a_{0, j}^{+}\left(T_{0, j}^{4}-\left(T_{0, j}+\delta T_{j}\right)^{4}\right) .
\end{aligned}
$$

Expanding the terms results in numerous instances of $T_{0}^{4}-$ $\left(T_{0}+\delta T\right)^{4}$. We can then approximate this as

$$
\begin{aligned}
T_{0}^{4}-\left(T_{0}+\delta T\right)^{4} & =T_{0}^{4}-\left(T_{0}^{4}+4 T_{0}^{3} \delta T+6 T_{0}^{2} \delta T^{2}\right. \\
\left.+4 T_{0}^{1} \delta T^{3}+T_{0}^{4}\right) & =-4 T_{0}^{3} \delta T-6 T_{0}^{2} \delta T^{2}-4 T_{0}^{1} \delta T^{3} \\
= & -4 T_{0}^{3} \delta T+O\left(\delta T^{2}\right), \approx-4 T_{0}^{3} \delta T .
\end{aligned}
$$


Eq. (A7) then becomes

$$
\begin{aligned}
A_{\text {net }, j, 0} & =\sigma a_{j}^{-} \sum_{n=1}^{j-1}\left[a_{n}^{-}\left(-4 T_{0, n}^{3} \delta T_{n}\right) \prod_{m=n+1}^{j-1} t_{m}^{-}\right] \\
& +\sigma a_{j}^{+}\left(\sum_{n=j+1}^{N-1}\left[a_{n}^{+}\left(-4 T_{0, n}^{3} \delta T_{n}\right) \prod_{m=j+1}^{n-1} t_{m}^{+}\right]\right) \\
& +\sigma a_{j}^{+}\left(a_{\text {surf }}^{+}\left(-4 T_{0, \text { surf }}^{3} \delta T_{\text {surf }}\right) \prod_{m=j+1}^{N-1} t_{m}^{+}\right) \\
& -\sigma a_{j}^{-}\left(-4 T_{0, j}^{3} \delta T_{j}\right)-\sigma a_{j}^{+}\left(-4 T_{0, j}^{3} \delta T_{j}\right) \\
& =-4 \sigma a_{j}^{-} \sum_{n=1}^{j-1}\left[a_{n}^{-}\left(T_{0, n}^{3} \delta T_{n}\right) \prod_{m=n+1}^{j-1} t_{m}^{-}\right] \\
& -4 \sigma a_{j}^{+}\left(\sum_{n=j+1}^{N-1}\left[a_{n}^{+} T_{0, n}^{3} \delta T_{n} \prod_{m=j+1}^{n-1} t_{m}^{+}\right]\right. \\
& \left.+a_{\text {surf }}^{+} T_{0, \text { surf }}^{3} \delta T_{\text {surf }} \prod_{m=j+1}^{N-1} t_{m}^{+}\right) \\
& +4 \sigma\left(a_{j}^{-} T_{0, j}^{3} \delta T_{j}+a_{j}^{+} T_{0, j}^{3} \delta T_{j}\right)
\end{aligned}
$$

Thus,

$$
\begin{aligned}
\frac{1}{4 \sigma} A_{\text {net }, j, 0}= & -a_{j}^{-} \sum_{n=1}^{j-1}\left[a_{n}^{-}\left(T_{0, n}^{3} \delta T_{n}\right) \prod_{m=n+1}^{j-1} t_{m}^{-}\right] \\
& -a_{j}^{+}\left(\sum_{n=j+1}^{N-1}\left[a_{n}^{+} T_{0, n}^{3} \delta T_{n} \prod_{m=j+1}^{n-1} t_{m}^{+}\right]\right. \\
+ & \left.a_{\text {surf }}^{+} T_{0, \text { surf }}^{3} \delta T_{\text {surf }} \prod_{m=j+1}^{N-1} t_{m}^{+}\right) \\
& +\left(a_{j}^{-} T_{0, j}^{3} \delta T_{j}+a_{j}^{+} T_{0, j}^{3} \delta T_{j}\right) .
\end{aligned}
$$

Consider this for every atmospheric layer. This system of linear equations can be written as

$$
\frac{1}{4 \sigma} \mathbf{A}_{\text {net, } 0}=\Lambda \boldsymbol{\delta} \mathbf{T}
$$

where,

$\mathbf{A}_{\text {net }, 0}=\left[\begin{array}{c}A_{\text {net }, 1,0} \\ A_{\text {net }, 2,0} \\ \vdots \\ A_{\text {net }, N-1,0} \\ A_{\text {net }, N, 0}\end{array}\right]$,

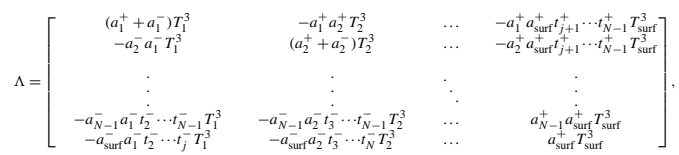

and,

$$
\delta \mathbf{T}=\left[\begin{array}{c}
\delta T_{1} \\
\delta T_{2} \\
\vdots \\
\delta T_{N-1} \\
\delta T_{N}
\end{array}\right] .
$$

Then Eq. (7) can be solved for $\boldsymbol{\delta} \mathbf{T}$ :

$\boldsymbol{\delta} \mathbf{T}=\frac{1}{4 \sigma} \Lambda^{-\mathbf{1}} \mathbf{A}_{\text {net }, \mathbf{0}}$,

which can be used to solve for the equilibrium temperature at each atmospheric layer and at the surface:

$\mathbf{T}_{\mathbf{E}}=\mathbf{T}_{\mathbf{0}}+\delta \mathbf{T}$

\section{A1 Diagnosing absorptivity}

The absorptivity is diagnosed as follows. The absorbed radiation $A_{b}$ for a layer $j$ is given by

$$
\begin{aligned}
A_{b} & =F_{\mathrm{LW}, j+1}^{+}-F_{\mathrm{LW}, j}^{+}, \\
& =a_{j}^{+} F_{\mathrm{LW}, j+1}^{+}-a_{j}^{+} \sigma T_{j}^{4},
\end{aligned}
$$

so that

$$
\begin{aligned}
& a_{j}^{+}\left(F_{\mathrm{LW}, j+1}^{+}-\sigma T_{j}^{4}\right)=F_{\mathrm{LW}, j+1}^{+}-F_{\mathrm{LW}, j}^{+}, \\
& a_{j}^{+}=\frac{F_{\mathrm{LW}, j+1}^{+}-F_{\mathrm{LW}, j}^{+}}{F_{\mathrm{LW}, j+1}^{+}-\sigma T_{j}^{4}}
\end{aligned}
$$

and, similarly,

$a_{j}^{-}=\frac{F_{\mathrm{LW}, j}^{-}-F_{\mathrm{LW}, j+1}^{-}}{F_{\mathrm{LW}, j}^{-}-\sigma T_{j}^{4}}$.

The upward $\left(a_{+}\right)$and downward $\left(a^{-}\right)$absorption coefficients are different because the spectral intensities of radiation incident on the layer are different. The upward propagating longwave radiation's spectra is heavily influenced by the emission spectra of water vapour and the surface, whereas the downward propagating radiation's spectra mainly emanates from the well-mixed greenhouse gases. 


\section{A2 Implementation of the algorithm}

To implement the algorithm, the troposphere is taken to be a single level in the model. The tropopause temperature is taken to be the level temperature. The temperature adjustment for the level is scaled by a factor of $1 / 4$ and applied at the surface. The pseudo-adiabatic lapse rate is followed from the adjusted surface up to the tropopause (if the tropopause is colder, the pseudo-adiabat is followed to the lowest level which exceeds the pseudo-adiabatic temperature profile).

However, this algorithm cannot lower the tropopause in a warming atmosphere. To account for this, we perform the algorithm again but treat the atmosphere from the surface to the layer below the tropopause as a single layer. The temperature adjustment is then only applied to the tropopause (if there is a warming). 
Acknowledgements. We thank Ty Robinson for help with SMART and discussions of the theory behind it. Financial support was received from the Natural Sciences and Engineering Research Council of Canada (NSERC) CREATE Training Program in Interdisciplinary Climate Science at the University of Victoria (UVic) and a University of Victoria graduate fellowship to B. Byrne and NSERC Discovery grant to C. Goldblatt. This research was enabled by the use of computing resources provided by WestGrid and Compute/Calcul Canada.

Edited by: Y. Godderis

\section{References}

Brewer, A.: Evidence for a world circulation provided by the measurements of helium and water vapour distribution in the stratosphere, Q. J. Roy. Meteor. Soc., 75, 351-363, doi:10.1002/qj.49707532603, 1949.

Brown, L. R., Sung, K., Benner, D. C., Devi, V. M., Boudon, V., Gabard, T., Wenger, C., Campargue, A., Leshchishina, O., Kassi, S., Mondelain, D., Wang, L., Daumont, L., Regalia, L., Rey, M., Thomas, X., Tyuterev, V. G., Lyulin, O. M., Nikitin, A. V., Niederer, H. M., Albert, S., Bauerecker, S., Quack, M., O'Brien, J. J., Gordon, I. E., Rothman, L. S., Sasada, H., Coustenis, A., Smith, M. A. H., Carrington Jr., T., Wang, X.-G., Mantz, A. W., and Spickler, P. T.: Methane line parameters in the HITRAN2012 database, J. Quant. Spectrosc. Ra., 130, 201-219, doi:10.1016/j.jqsrt.2013.06.020, 2013.

Byrne, B. and Goldblatt, C.: Radiative forcing at high concentrations of well-mixed greenhouse gases, Geophys. Res. Lett., 41, 152-160, doi:10.1002/2013GL058456, 2014.

Donn, W. L., Donn, B. D., and Valentine, W. G.: On the early history of the Earth, Geol. Soc. Am. Bull., 76, 287306, doi:10.1130/0016-7606(1965)76[287:OTEHOT]2.0.CO;2, 1965.

Driese, S. G., Jirsa, M. A., Ren, M., Brantley, S. L., Sheldon, N. D., Parker, D., and Schmitz, M.: Neoarchean paleoweathering of tonalite and metabasalt: implications for reconstructions of $2.69 \mathrm{Gyr}$ early terrestrial ecosystems and paleoatmospheric chemistry, Precambrian Res., 189, 1-17, doi:10.1016/j.precamres.2011.04.003, 2011.

Feulner, G.: The faint young sun problem, Rev. Geophys., 50, RG2006, doi:10.1029/2011RG000375, 2012.

Goldblatt, C.: Bistability of atmospheric oxygen, the Great Oxidation and climate, Ph. D. thesis, Univ. East Anglia, 77-98, 2008.

Goldblatt, C., Claire, M. W., Lenton, T. M., Matthews, A. J., Watson, A. J., and Zahnle, K. J.: Nitrogen-enhanced greenhouse warming on early Earth, Nat. Geosci., 2, 891-896, doi:10.1038/ngeo692, 2009.

Gough, D.: Solar interior structure and luminoscity variations, Sol. Phys., 74, 21-34, doi:10.1007/BF00151270, 1981.

Haqq-Misra, J. D., Domagal-Goldman, S. D., Kasting, P. J., and Kasting, J. F.: A revised, hazy methane greenhouse for the archean earth, Astrobiology, 8, 1127-1137, doi:10.1089/ast.2007.0197, 2008.

Hasenkopf, C. A., Freedman, M. A., Beaver, M. R., Toon, O. B., and Tolbert, M. A.: Potential climatic impact of organic haze on early earth, Astrobiology, 11, 135-149, doi:10.1089/ast.2010.0541, 2011.

IPCC: Climate Change 2013: The Scientific Basis. Contribution of Working Group I to the Fifth Assessment Report of the Intergovernmental Panel on Climate Change, Cambridge University Press, Cambridge, UK, and New York, NY, USA, 659-740, 2013.

Kasting, J.: Methane and climate during the Precambrian era, Precambrian Res., 137, 119-129, doi:10.1016/j.precamres.2005.03.002, 2005. The difference in absorption by $\mathrm{CO} 2$ and $\mathrm{H} 2 \mathrm{O}$ is quite small between the two databases. A lthough, many new lines have been added to both $\mathrm{CO} 2$ and $\mathrm{H} 2 \mathrm{O}$ databases they do not provide a large radiative effect in the regime we examined. The differences between HITRAN versions results in a small increase to the greenhouse strength between versions, increasing the surface temperature by roughly $1 \mathrm{~K}$ in the regimes we examined.

Kasting, J., Zahnle, K., and Walker, J.: Photochemistry of methane in the Earth's early atmosphere, Precambrian Res., 20, 121-148, doi:10.1016/0301-9268(83)90069-4, 1983.

Kharecha, P., Kasting, J., and Siefert, J.: A coupled atmosphereecosystem model of the early Archean Earth, Geobiology, 3, 5376, doi:10.1111/j.1472-4669.2005.00049.x, 2005.

Kunze, M., Godolt, M., Langematz, U., Grenfell, J. L., HamannReinus, A., and Rauer, H.: Investigating the early Earth faint young Sun problem with a general circulation model, Planet. Space Sci., 98, 77-92, doi:10.1016/j.pss.2013.09.011, 2014.

Manabe, S. and Wetherald, R.: Thermal equilibrium of the atmosphere with a given distribution of relative humidity, J. Atmos. Sci., 24, 241-259, doi:10.1175/15200469(1967)024<0241:TEOTAW>2.0.CO;2, 1967.

Meadows, V. and Crisp, D.: Ground-based near-infrared observations of the Venus nightside: the thermal structure and water abundance near the surface, J. Geophys. Res.-Planet, 101, 45954622, doi:10.1029/95JE03567, 1996.

Newell, R. and Gould-Stewart, S.: A stratospheric fountain, J. Atmos. Sci., 38, 2789-2796, doi:10.1175/15200469(1981)038<2789:ASF>2.0.CO;2, 1981.

Pavlov, A., Kasting, J., Brown, L., Rages, K., and Freedman, R.: Greenhouse warming by $\mathrm{CH}_{4}$ in the atmosphere of early Earth, J. Geophys. Res.-Planet, 105, 11981-11990, doi:10.1029/1999JE001134, 2000.

Rossow, W., Henderson-Sellers, A., and Weinreich, S.: Cloud feedback - a stabilizing effect for the early Earth, Science, 217, 12451247, doi:10.1126/science.217.4566.1245, 1982.

Rothman, L. S., Gordon, I. E., Babikov, Y., Barbe, A., Benner, D. C., Bernath, P. F., Birk, M., Bizzocchi, L., Boudon, V., Brown, L. R., Campargue, A., Chance, K., Cohen, E. A., Coudert, L. H., Devi, V. M., Drouin, B. J., Fayt, A., Flaud, J. M., Gamache, R. R., Harrison, J. J., Hartmann, J. M., Hill, C., Hodges, J. T., Jacquemart, D., Jolly, A., Lamouroux, J., Le Roy, R. J., Li, G., Long, D. A., Lyulin, O. M., Mackie, C. J., Massie, S. T., Mikhailenko, S., Mueller, H. S. P., Naumenko, O. V., Nikitin, A. V., Orphal, J., Perevalov, V., Perrin, A., Polovtseva, E. R., Richard, C., Smith, M. A. H., Starikova, E., Sung, K., Tashkun, S., Tennyson, J., Toon, G. C., Tyuterev, V. G., and Wagner, G.: The HITRAN2012 molecular spectroscopic database, J. Quant. Spectrosc. Ra., 130, 4-50, doi:10.1016/j.jqsrt.2013.07.002, 2013. 
Sagan, C. and Mullen, G.: Earth and Mars - evolution of atmospheres and surface temperatures, Science, 177, 52-56, doi:10.1126/Science.177.4043.52, 1972.

Trainer, M., Pavlov, A., Curtis, D., McKay, C., Worsnop, D., Delia, A., Toohey, D., Toon, O., and Tolbert, M.: Haze aerosols in the atmosphere of early earth: manna from heaven, Astrobiology, 4, 409-419, doi:10.1089/ast.2004.4.409, 2004.

Trainer, M. G., Pavlov, A. A., DeWitt, H. L., Jimenez, J. L., McKay, C. P., Toon, O. B., and Tolbert, M. A.: Organic haze on Titan and the early Earth, P. Natl. Acad. Sci. USA, 103, 1803518042, doi:10.1073/pnas.0608561103, 2006.
Wolf, E. T.: Interactive comment on "Diminished greenhouse warming from Archean methane due to solar absorption lines", edited by: Byrne, B. and Goldblatt, C., Clim. Past Discuss., 10, C2137-C2137, 2014.

Wolf, E. T. and Toon, O. B.: Fractal organic hazes provided an ultraviolet shield for early Earth, Science, 328, 1266-1268, doi:10.1126/Science.1183260, 2010.

Wolf, E. T. and Toon, O. B.: Hospitable archean climates simulated by a general circulation model, Astrobiology, 13, 656-673, doi:10.1089/ast.2012.0936, 2013.

Zahnle, K.: Photochemistry of methane and the formation of hydrocyanic acid (HCN) in the earth's early atmosphere, J. Geophys. Res., 91, 2819-2834, doi:10.1029/JD091iD02p02819, 1986. 